\title{
The Role of Corporate Social Responsibility in the Wine Industry: The Case Study of Veneto and Friuli Venezia Giulia
}

\author{
Lisa Pizzol ${ }^{1}\left(\mathbb{D}\right.$, Gloria Luzzani ${ }^{2, *}$, Paolo Criscione ${ }^{3}\left(\mathbb{D}\right.$, Luca Barro $^{4}$, Carlo Bagnoli ${ }^{4}$ and Ettore Capri ${ }^{5}(\mathbb{D}$ \\ 1 GreenDecision srl, 30172 Venice, Italy; lisa.pizzol@greendecision.eu \\ 2 Center for Corporate Responsibility and Sustainability (CCRS), University of Zürich, \\ CH-8001 Zürich, Switzerland \\ 3 DESAM Ingegneria e Ambiente srl, 30172 Venice, Italy; criscione@desam.it \\ 4 Department of Management, Ca' Foscari University of Venice, 30123 Venice, Italy; 841672@stud.unive.it (L.B.); \\ bagnoli@unive.it (C.B.) \\ 5 European Observatory on Sustainable Agriculture (OPERA), Università Cattolica del Sacro Cuore, \\ 29122 Piacenza, Italy; ettore.capri@unicatt.it \\ * Correspondence: gloria.luzzani@ccrs.uzh.ch
}

check for

updates

Citation: Pizzol, L.; Luzzani, G.; Criscione, P.; Barro, L.; Bagnoli, C.; Capri, E. The Role of Corporate Social Responsibility in the Wine Industry: The Case Study of Veneto and Friuli Venezia Giulia. Sustainability 2021, 13, 13230. https://doi.org/10.3390/ su132313230

Academic Editor: Jean-Marie Cardebat

Received: 6 October 2021

Accepted: 22 November 2021

Published: 29 November 2021

Publisher's Note: MDPI stays neutral with regard to jurisdictional claims in published maps and institutional affiliations.

Copyright: (c) 2021 by the authors. Licensee MDPI, Basel, Switzerland. This article is an open access article distributed under the terms and conditions of the Creative Commons Attribution (CC BY) license (https:/ / creativecommons.org/licenses/by/ $4.0 /)$.
Abstract: This study aimed to investigate the awareness of Corporate Social Responsibility (CSR) among wineries located in the Italian regions of Veneto and Friuli Venezia Giulia (FVG) (1), (2) the obstacles (3) and market drivers of its implementation (4), the practices and range of actions that are concretely implemented in the field of CSR (5), the implications that this management approach can have on company performance (6), and the communication tools used. The methodology adopted is based on a qualitative approach integrated with quantitative measures. In total, 28 wineries participated in the study. The results show that all of the wineries were aware of the importance of implementing CSR, although they mainly refer to environmental issues. Sponsorship in fair trade activities is considered the most relevant market driver, while Italian consumers are generally perceived as not particularly interested in sustainable wine production. The practices implemented are mainly focused on reducing environmental impact. Interesting insights have emerged from this study, such as an unusual disparity between theoretical knowledge and practical implementation of socially responsible activities, a tendency to adapt the entrepreneurial style towards CSR, as well as a fundamental willingness to implement good practices that go beyond the legal requirements currently in force.

Keywords: corporate sustainability; ecological drivers; sustainability practices; food chain; wine industry; CSR activities

\section{Introduction}

The consumers' concern on environmental and social issues of products and organizations is pushing companies to recognize their moral and legal obligations towards society, as well as to study, account, and mitigate their environmental impacts [1]). Entrepreneurs' awareness about their role in society, as well as the impacts of their activities on the territory, intended as a mix of environmental, social, and cultural resources, is increasing and calls for more responsibility. Responsible entrepreneurship is defined as a managerial approach that categorically avoids any negative impact on stakeholders (investors, employees, suppliers, consumers, and the local community); if any harm is caused to stakeholders, the company must remedy it as soon as it is recognized [2]. Corporate Social Responsibility (CSR) is a set of responsible practices and behaviors that shift organizations towards more responsible practices. Organizations can adopt CSR as a way to strategically "integrate economic, social and environmental concerns into their business strategies, their management tools and their activities, going beyond compliance and investing more into human, social and environmental capital" [3]. Therefore, CSR includes responsible practices related to different organizational operations areas: i.e., internal practices, such as 
human resources management and working environment conditions; external practices, such as community involvement, the promotion of the territory and its social, cultural, and economic development; environmental practices to reduce organization environmental impacts, resource withdrawal, and waste production.

In 2015 the United Nations adopted the Agenda 2030, a roadmap with 17 Sustainable Development Goals (SDGs), that should be pursued by nations, organizations, and citizens to meet sustainable development [4]. Agenda 2030 explicitly encourages companies, especially large and transnational companies, to adopt sustainable practices and to integrate sustainability information into their reporting cycle. Specifically, it calls for sustainable food production systems and resilient agricultural practices that increase productivity and production, while protecting the ecosystems and strengthening the adaptation capacity. Wine production must cope with extraordinary challenges, which are strictly connected to its impact and activities: the dependency on environmental resources that characterized the agricultural sector place farmers and winemakers among the most exposed categories to market risk and quality loss. For instance, Mozell and Thach [5] have shown that climate change may lead to a relevant shift in grape growing regions, while water stress could impact on yields and consequentially on wine quality and wine companies' income [6]. On the other hand, vineyard management is one example of landscape management services provided by agricultural operators: a better management of cultivated areas reflects into an improvement of biodiversity-mediated ecosystem services [7], which are the main provider of benefits and amenities [8]. Furthermore, the landscape designed by vineyard management and the relation among wine production and the local territory are a relevant part of local tradition as physical and cultural landscape, and, therefore, could contribute to preserving and promoting cultural heritage, while attracting wine tourism and fostering communities' growth [9].

Among all agricultural industries, the wine industry has seen a huge proliferation of initiatives focused on the assessment and the improvement of sustainability [10]. The companies are striving to answer to multiple environmental and social issues that are currently threatening the economic balance of the wine market. In most cases, the initiatives are promoted by trade associations or governments, with the aim to increase local and national brand reputations while reducing environmental and social burdens. These programs can have a different scope and apply diverse methodologies, but it is possible to reconduct them to two different typologies: (i) programs that certify the winegrowing process as, for instance, organic production [11], or integrated production [12], (ii) programs that certify the sustainability at product or winery level [13-15]. Usually, they are conceived as voluntary programs, which may vary widely in terms of methodologies and objectives. Some of these programs (such as VIVA Sustainability and Culture) do also adopt sciencebased indicators to assess the water, carbon, and agronomic footprints of a wine bottle from a winery [16-19]. After the assessment, third-party verification could be required before the promoting institutions release the final program label or certification [19]. There also exists a vast array of studies about the environmental and social impact of wine production: special interest has been dedicated to the water footprint of wine $[20,21]$ and the comparative studies on the carbon footprint of wine [22-25]. Furthermore, the use of multiple indicators has been proposed to compare the environmental burdens of conventional and organic vineyard management [26].

Despite the wide offer of sustainability programs and assessment methodologies, the adherence is still low [27]. This could be attributed to a lack of internal competences and a proper organizational structure, as they are mainly family businesses or micro-small enterprises [28]. For those Italian wineries that do not adhere to a certification program, the implementation of sustainability is mainly defensive and generally lacks a proactive and fully integrated strategy, while investments in sustainability are mainly in the production process and limited to the environmental dimension [27].

Santini et al. [29] found that the key relevant research question, with respect to wine sustainability, is "under what conditions sustainability happens"; therefore, more research focused on wine producers is needed in order to increase knowledge about their adoption 
and evaluation of sustainable practices [30]. De Steur et al. [31] has investigated drivers, adoption and evaluation of sustainability practices of small and medium wine enterprises of two Italian regions: Emilia Romagna and Tuscany. Their results showed that internal drivers (environmental sustainability and heritage) were more relevant than external ones, and the key obstacles were labor and investments costs; the adoption of sustainable practices were substantially different among companies. Nevertheless, sustainability drivers and adoption vary significantly across regions and companies' size [32-34], and more studies are needed to better describe the fragmented reality of the Italian wine system, which encompasses both poorly mechanized production systems and intensive viticulture. The Italian regions of Veneto and Friuli Venezia Giulia have seen an increase in grape production since the Prosecco designation of origin area has been widened. The increase of wine production in those regions has contributed to the rise of public concern about pesticide treatment intensification and residents' exposure, which resulted, in the case of the Veneto region, into a request for a referendum about pesticide use in the local areas $[35,36]$. Over the last years, research has described [37] and analyzed how the territorial and landscape consequences of vineyard expansion in the Veneto Region and Prosecco areas have triggered social conflicts [38-40]. Basso and Fregolent [41] have also proposed options to the monocultures, in order to cope with the correlated environmental and social issue.

The objective of this work is to investigate awareness, market drivers, obstacles, CSR practices, and business performance implications with respect to Corporate Social Responsibility of wine companies located in Veneto and Friuli Venezia Giulia (Italy). The present study contributes to existing studies on sustainability practices in Italian regions, to provide a better picture and understanding of the range of sustainable and socially responsible activities that Italian wine companies have implemented, or may implement in the future, and how they vary across regions.

\section{Materials and Methods}

An online questionnaire was developed and submitted to wine companies located in the Veneto and FVG regions (Italy) in order to verify their knowledge about Corporate Social Responsibility, their perception of this topic in relation to the main market trends, the range of actions that can be concretely implemented in the field of CSR, and the most relevant and effective available tools to communicate companies' sustainable and socially responsible commitments.

The methodology for the collection of suitable information from the wine companies adopted in the present study has been adapted from Gabzdylova et al. [42], and it is based on qualitative research methods integrated by quantitative measures. The conceptual model of the study and its relation with the different sections of the developed questionnaire is presented in Figure 1, while the description of the case study is reported in Section 2.1.

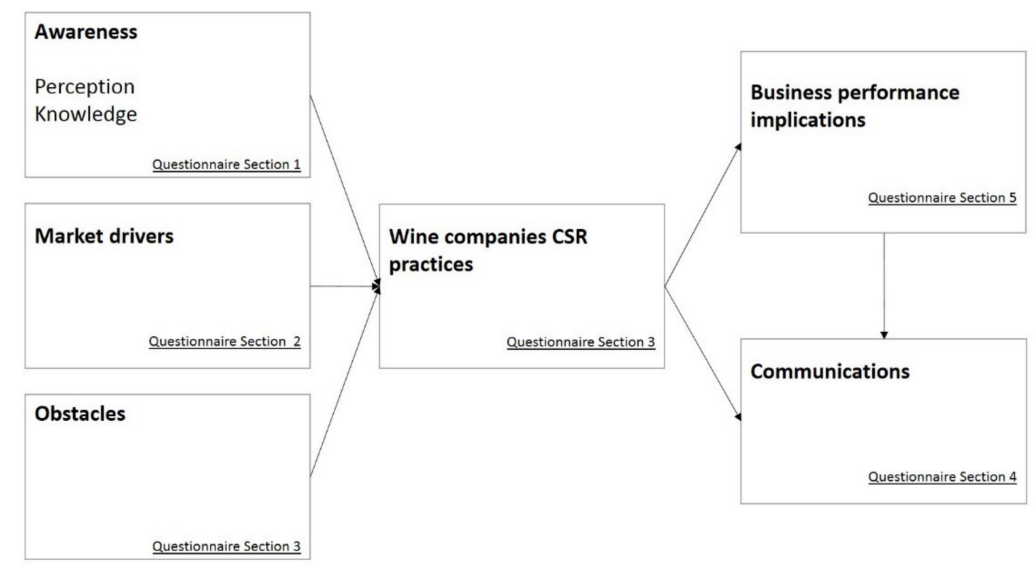

Figure 1. Conceptual model of the study and its relation with the different sections of the developed questionnaire. 
Finally, the study applies the typology matrix proposed by Gabzdylova et al. (2009) to investigate the extent of sustainability practices implemented by wineries on the basis of the sustainability drivers they are facing.

\subsection{The Wine Sector in Veneto and Friuli Venezia Giulia (Italy)}

The wide distribution and geographical concentration of wine production in Veneto and Friuli Venezia Giulia, along with the wine-growing areas of Piedmont, Tuscany, Puglia, and Sicily, have relevant interactions with local ecosystems. In 2018, Veneto was the region with the highest amount of wine production in Italy, with 12.9 million hectolitres $(25 \%$ of the total amount produced in Italy), while Friuli Venezia Giulia accounts for 1.7 million hectolitres. Together they represent $27 \%$ of the total amount of Italian wine production. In the last years, Veneto wine production has grown significantly. In 2018, the regional production increased $+52 \%$ with respect to the previous year and $+48 \%$ with respect to the average of the last 10 years, confirming its economic relevance for Veneto development. According to Istituto Nazionale di [43], the area planted with vines in Veneto in 2018 grew by 2300 hectares: from 84,700 to 87,000 hectares.

In Friuli Venezia Giulia the area planted with vines in 2018 reached 25,073 ha (distributed among 5767 farms), with an increase of about $20 \%$ on the planted area that was recorded in 2013. The average farm size is lower than $5 \mathrm{ha}$, while only eight wine cooperatives are responsible for $35-40 \%$ of the total production.

The relevant increase in the cultivated areas is posing several issues and the urgency to seek new balances among the environment and the local communities.

\subsection{Questionnaire Development}

Primary data were collected through an online questionnaire, fully available in the Supplementary Materials, composed of 20 questions, including multiple-choice questions, open and semi-open questions, as well as scales of assessment or agreement on certain aspects. The interview included six Likert scale questions (scaled from " 1 Not at all/Very low" to "Very much/Very high").

The developed questions are divided into different themes, which represent the main aspects to be assessed and shown in the conceptual model (Figure 1):

1. Knowledge/perception of Corporate Social Responsibility. This section, composed of four questions, aims at assessing the wineries' awareness level and perceptions of CSR;

2. Market drivers. This section, composed of five questions, aims at assessing what the main external drivers are and what is the nature of internal drivers towards CSR implementation;

3. Practices of Corporate Social Responsibility. This section, composed of five questions, aims at assessing the actions and strategies carried out by the companies to implement CSR, along with possible obstacles and incentives;

4. Communication. This section, composed of three questions, aims at assessing what the communication channels are and actions that are considered more suitable for the promotion of CSR;

5. Business performance implications. This section, composed of three questions, aims at evaluating the companies' perceived and assessed benefits in implementing and communicating CSR actions.

Additionally, the questionnaire includes an initial section introducing the objectives of the questionnaire and a final section aimed at collecting general information about the responding company (region, type of company, annual wine quantity etc.).

A web-based version of the questionnaire has been developed using the Google Forms portal. The online format was chosen for the immediacy of access via a simple hyperlink, the possibility of filling it in directly online, and the tool functionality that enables data collection in an online database. The questionnaire was submitted, from July to August 2019 , to the attention of the owner, the director, and the oenologist of 120 wine companies 
based in the Friuli Venezia Giulia (n. 60) and Veneto (n. 60) regions. A kind reminder for the filling in of the questionnaire was sent every 15 days.

Contacted winery companies were selected to cover different companies' sizes, geographical distribution within the regions, and companies representing both the national market and the global one. The objective was to have a heterogeneous set of companies, which was representative of the Veneto and Friuli Venezia Giulia regions. Considering the average annual revenue of the wineries invited to take part in the survey, it has been estimated that they represented between $6 \%$ to $10 \%$ of the wine sector in Veneto and Friuli Venezia Giulia.

\section{Results}

In total, 28 (FVG: 18; Veneto: 10) of the 120 questioned wine companies participated in the survey. The rate of response, equal to $23 \%$, is consistent with the ones found in other studies. Table 1 reports the summary of respondents' job position and company location, while Table 2 describes the annual revenue, the number of bottles produced per year, and the average percentage of exported wine bottles among the companies belonging to the specific annual revenue range reported in the first column.

Table 1. Summary of respondents' job position and company location.

\begin{tabular}{ccccc}
\hline Region & Owner & Director & Oenologist & Total \\
\hline FVG & 12 & 6 & 1 & 19 \\
VENETO & 3 & 5 & 1 & 9 \\
& 15 & 11 & 2 & 28 \\
\hline
\end{tabular}

Table 2. Companies' annual revenue (first column), sum of the number of bottles produced per year by the companies falling in the specific annual revenue range reported in the first column (third column), and average percentage of exported wine bottles among the companies belonging to the specific annual revenue range reported in the first column (last column).

\begin{tabular}{cccc}
\hline & $\begin{array}{c}\text { Number of } \\
\text { Wine Companies }\end{array}$ & $\begin{array}{c}\text { Sum of Produced } \\
\text { Wine Bottles }\end{array}$ & $\begin{array}{c}\text { Average \% } \\
\text { of Export }\end{array}$ \\
\hline Friuli Venezia Giulia & $\mathbf{1 9}$ & $\mathbf{3 , 2 4 7 , 5 0 0}$ & $\mathbf{2 2}$ \\
\hline 1. Less then 200,000 & 6 & 172,500 & 29 \\
2. From 200,000 to 500,000 & 4 & 365,000 & 25 \\
3. From 500,000 to 1 milion & 4 & 760,000 & 12 \\
4. From 1 to 2 milion & 3 & 440,000 & 46 \\
5. From 2 to 5 milion & 1 & 310,000 & 3 \\
$7 .>10$ milion & 1 & $1,200,000$ & 36 \\
Veneto & $\mathbf{9}$ & $\mathbf{4 9 , 8 4 0 , 0 0 0}$ & 5 \\
\hline 1. Less then 200,000 & 2 & 100,000 & 53 \\
2. From 200,000 to 500,000 & 1 & 200,000 & 40 \\
3. From 500,000 to 1 milion & 2 & 240,000 & 25 \\
5. From 2 to 5 milion & 1 & 800,000 & 39 \\
6. From 5 to 10 milion & 1 & $5,500,000$ & $\mathbf{2 7}$ \\
\hline 7. >10 milion & 2 & $43,000,000$ & \\
\hline Total & $\mathbf{2 8}$ & $\mathbf{5 3 , 0 8 7 , 5 0 0}$ &
\end{tabular}

The respondents' sample is heterogeneous in terms of annual revenue, business features, and number of bottles produced per year as reported in Table 2.

In coherence with the research design shown in Figure 1, the results of the studied issues are presented and discussed in the following sections: awareness about CSR, 
market drivers, obstacles, CSR practices, business performance implications of CSR, and its communication.

\subsection{Awareness about CSR}

In this section, the results of the study on the awareness of the features and practices of CSR among wine companies in the FVG and Veneto regions are presented. The replies to the question about what was the first approach to CSR (Q 1.3) differ among the interviewees: only two respondents (revenue from 500,000 $€$ to 2 million $€$ ) declared they did not have any approach to CSR, where the majority of the respondents stated that their first approach to CSR was seminars and congress participation and informational materials that they had received.

The results suggest that all the respondents agree on the existence of a certain degree of responsibility that wine companies have, with the majority of the respondents pointing out that being responsible is part of their entrepreneurial behavior. Despite this, only few respondents declaring that they are responsible entrepreneurs own a sustainability certification (Table 3). This suggests that entrepreneurial commitment to sustainability does not necessarily imply sustainability certifications or standard compliances: the perception of being a responsible entrepreneur may differ among company owners and is related to personal values and ethics.

Table 3. Sustainability certification obtained by the respondents. (SQNPI_ Sistema di Qualità Nazionale per la Produzione Integrata-Integrated Production; VIVA: VIVA La sostenibilità della vitivinicoltura in Italia (VIVA Sustainability and Culture).

\begin{tabular}{ccc}
\hline Certification & FVG & Veneto \\
\hline Biodiversity friend & & 1 \\
VIVA & 1 & 2 \\
SQNPI & 5 & 3 \\
No & 13 & 4 \\
\hline
\end{tabular}

To the open question "In your opinion, have wine companies any social responsibilities. Why?" (Q 1.2), all respondents answered "Yes", with different point of views: the majority of them mentioned environmental impact as the first issue, some also mentioned the importance of employees' well-being and safety of the workplace, and four respondents related wine companies responsibilities to economic and social aspects, such as impact on territory and the health of the local community and consumers. A quarter of the respondents did not provide any details about why, in their opinion, CSR was important to wine companies.

About half of the respondents consider themselves to be poorly informed about CSR (Q 1.1). Among those who answered they were poorly informed, seven (60\%) wine companies reported a revenue lower than 500,000 $€$. However, despite the declared low level of theoretical information available to respondents and their perception, their awareness about CSR aspects is very high, as documented by sustainability actions already in place (Figure 2). The box and whisker plot presented in Figure 2 shows to what extent the respondents consider the cited actions/aspects important on a scale from 1 (low) to 5 (high) with respect to CSR. The middle line of the box represents the median or middle number, the $\mathrm{x}$ in the box represents the mean, while the median divides the data set into a bottom half and a top half. The bottom line of the box represents the median of the bottom half or 1st quartile. The top line of the box represents the median of the top half or 3rd quartile. The whiskers (vertical lines) extend from the ends of the box to the minimum value and maximum value (the same graphical representation has been used for Figures 3, 5, 6 and 7). According to the results reported in Figure 2, the reduction of environmental impact is stated as the most important aspect to be implemented in order to be socially responsible: all respondents assigned to this aspect the highest degree of importance. Technological innovation and sustainability, employees' wellness, safety of the working environment, 
consumer's satisfaction, transparency, public reputation, business management, and environmental certification are considered highly and equally important. Ethical certification, equal opportunities, and organizational compliance are all considered to be on average important to very important, but have lower scores than the other elements.

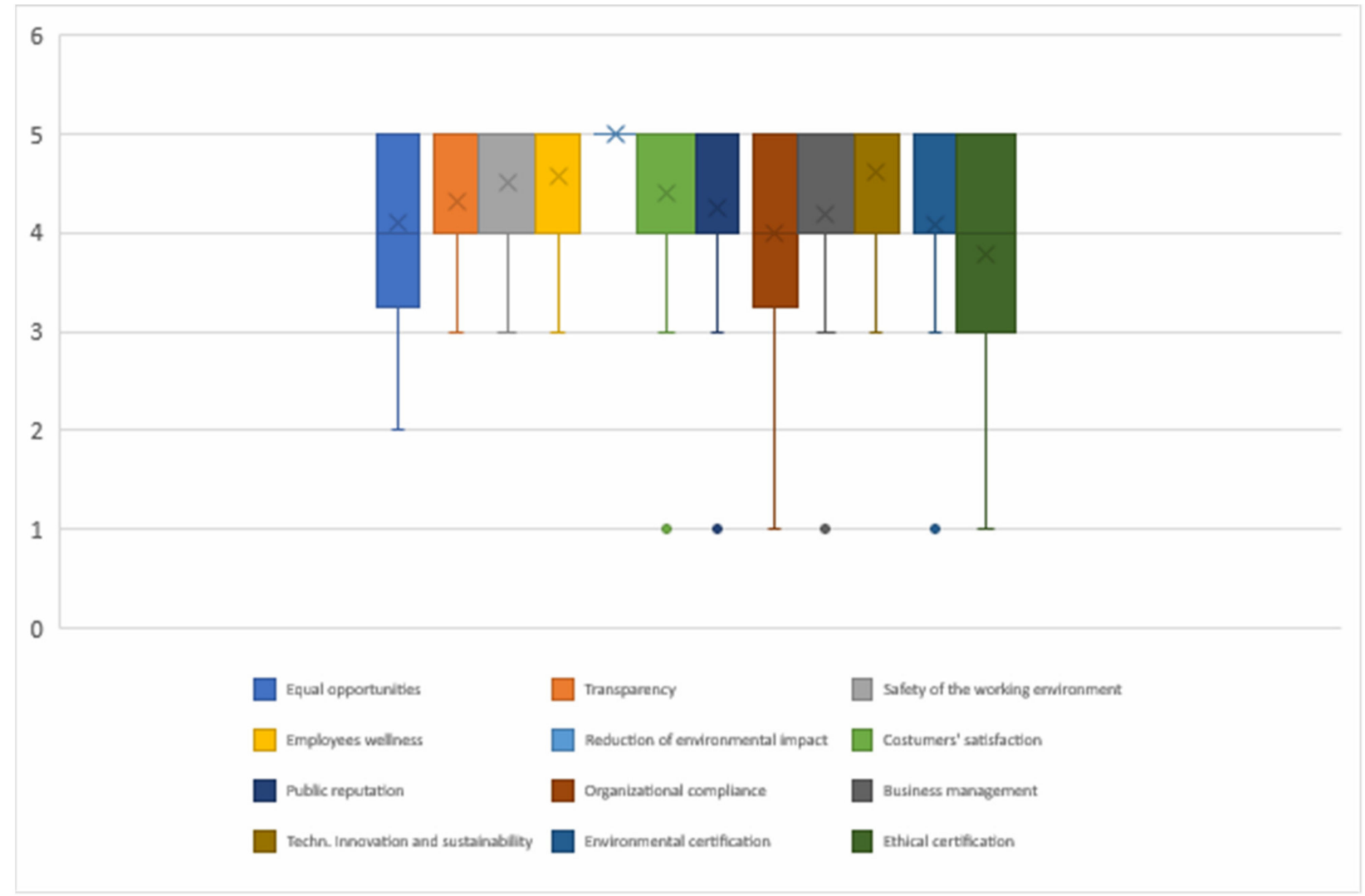

Figure 2. Actions/aspect of a responsible wine company (1 low importance; 5 high importance).

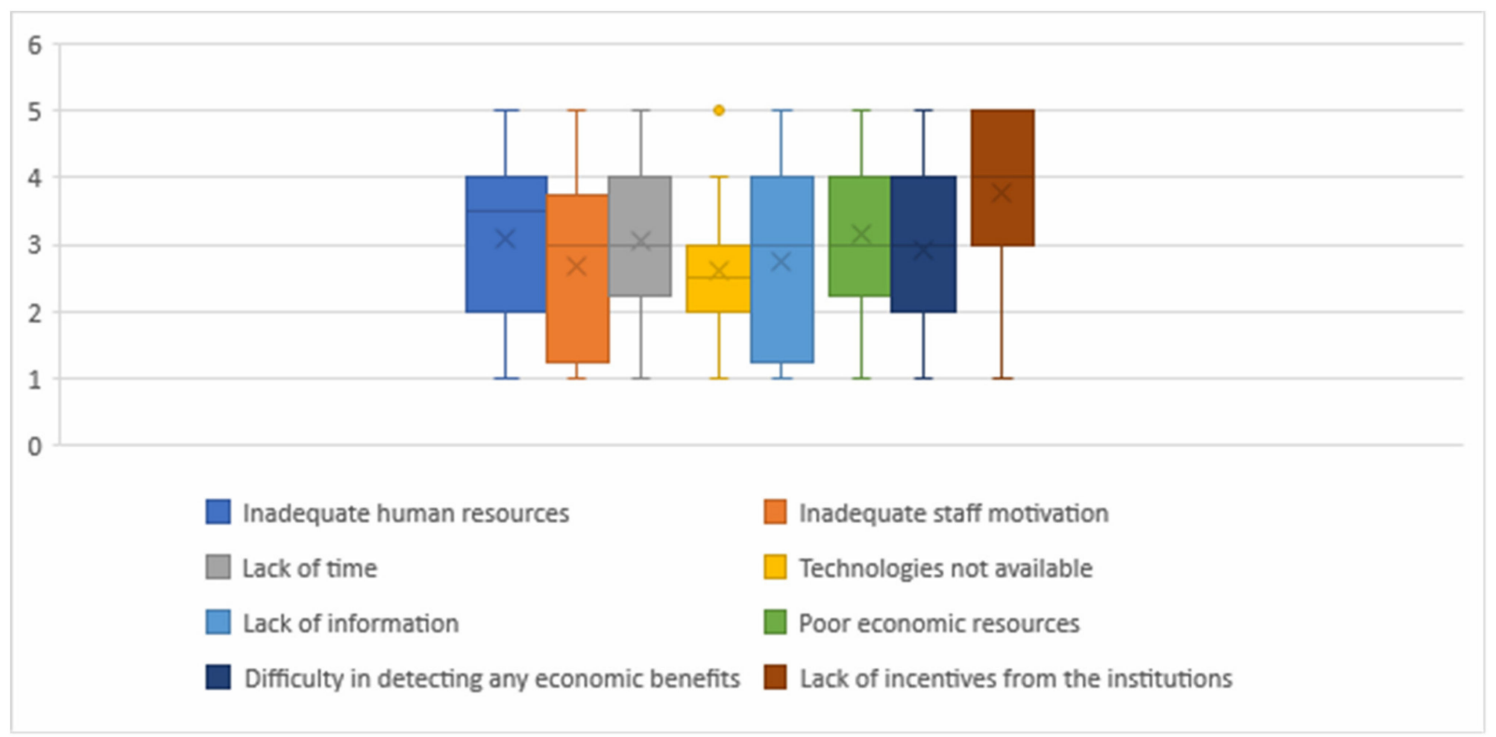

Figure 3. Obstacles to the implementation of CSR. The middle line of the box represents the median or middle number, the $\mathrm{x}$ in the box represents the mean, while the median divides the dataset into a bottom half and a top half. The bottom line of the box represents the median of the bottom half or 1st quartile. The top line of the box represents the median of the top half or 3rd quartile. The whiskers (vertical lines) extend from the ends of the box to the minimum value and maximum value. 


\subsection{Obstacles}

The findings provided by Q 3.4 suggest that the most relevant obstacle to the implementation of CSR in FVG and Veneto's wine industries is the lack of incentives from the public institutions, followed by the lack of time and poor economic resources (Figure 3). Inadequate staff motivation and lack of information show the wider answer distribution, confirming that they are strictly dependent on managerial personal interests and commitment that differs among companies. The absence of the skilled human resources are also a relevant obstacle to CSR implementation: this could be due to the intrinsic features of the FVG and Veneto wine companies that are mainly family business and small and medium enterprises.

\subsection{Market Drivers}

The results show that the first approach to CSR items are mainly driven by the willingness to implement sustainability in an innovative way, and, therefore, it is connected to personal/internal organizational reasons (Q 1.3). External drivers, such as the need to meet legal obligations, business partners, and customer requirements, seeking for tax incentives, and better access to credit, performed equally. On the other hand, almost all of the respondents stated that a higher sponsorship in trade fair activities could stimulate social responsibility actions of the companies in their territories, suggesting that the present ones are judged inadequate, which is also confirmed by the results shown in Figure 3. After sponsorships, the main market drivers towards CSR are: CSR training and consultancy and cooperation with local actors.

Finally, actual commitment to CSR practices is driven, in most of the cases, by corporate willingness. Only three respondents stated that, with their sustainable practices, they are responding to a market need, while one respondent declared that he decided to engage in CSR after having participated in an EU project that had pushed him towards a cultural shift.

In order to better investigate the effect of external requirements on orientation towards CSR, the questionnaire has focused the attention on the pressure posed by external stakeholders with respect to ethical issues, such as illegal hiring of wine labor and environmental requirements.

Since irregular work and labor exploitation are perceived as an emerging issue in some agricultural regions, the questionnaire investigated if the increasing attention posed by stakeholders on fair hiring practices is intended by the respondents as a real need or a wrong perception of the productive system (Q 2.1). Almost half of the respondents totally agree with the fact that this is a real need of the market, while only 3 of the respondents consider it is a wrong perception.

According to the answers to $Q 2.2$, Italian consumers are generally considered as not being particularly interested in sustainable wine production, some respondents declared that "there is lack of awareness" about sustainability themes, and others reported that "more informed consumers are more sensitive to sustainability thematic". It is interesting to notice that one respondent stated that "consumers' knowledge is strictly dependent on wine industry commitment to sustainability". A quarter of respondents stated that other factors, such as territoriality and origin have a higher impact on consumers' quality perception, one of them explained the concept as follow: "Mainly, wine must be good and its production should be transparent. The Italian wine consumer should be able to admire our territories and have a perception of beauty, as well as goodness". Furthermore, the respondents expect that the interest, with respect to sustainable wine, is overall increasing; this perception is coherent with the common (78\%) intention to modify the production process to meet the concerns of consumers who are sensitive to CSR.

\subsection{Wine Companies' CSR Practices}

Section 3 of the questionnaire was aimed at assessing companies' commitment to CSR by collecting information about actions undertaken to implement CSR. 
In Figure 4, the answers to $\mathrm{Q} 3.2$ concerning the degree of implementation (realized, planned, not planned) of different CSR actions are shown. Out of all 15 sustainability practices identified by the authors of this paper, the interviewed companies adopt 7 practices on average, with a standard deviation of 4 and a range of 14 practices.

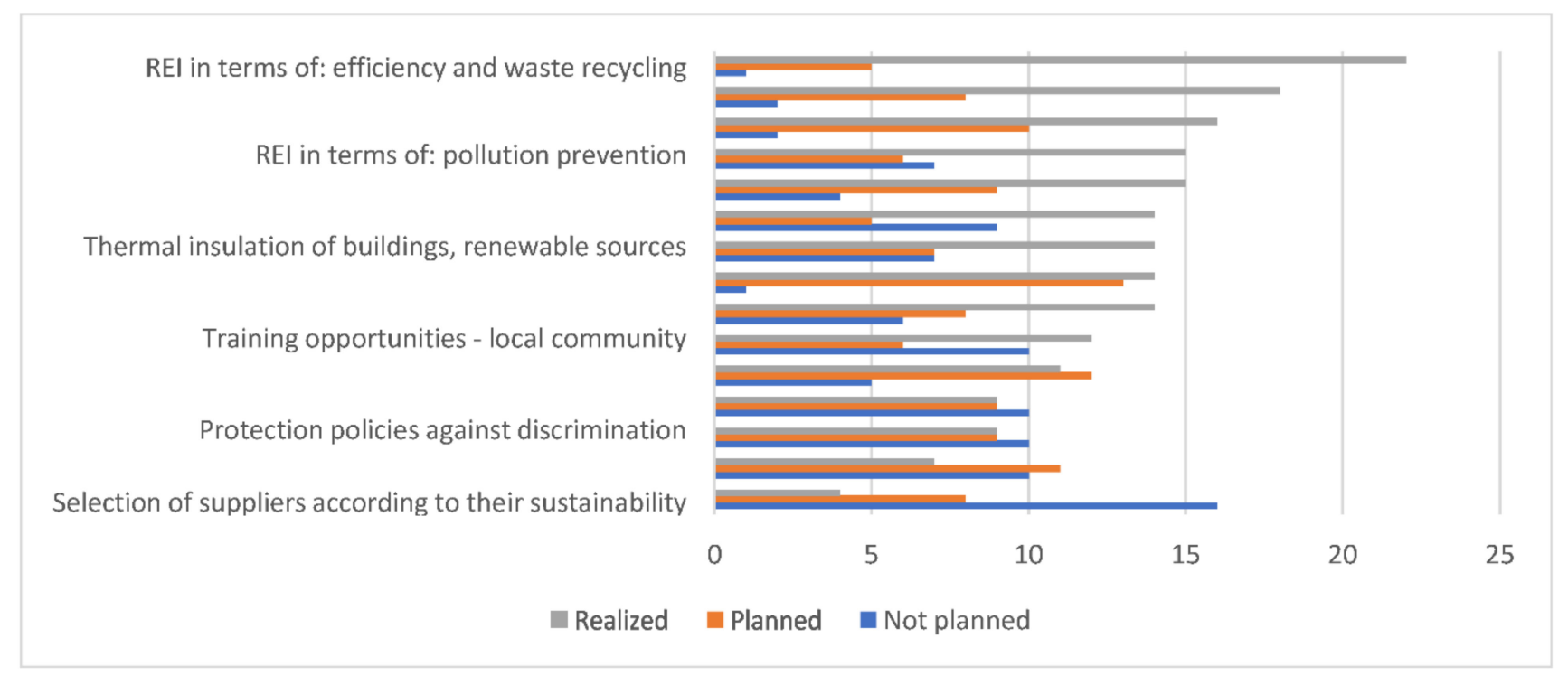

Figure 4. Degree of implementation of different CSR actions and aspects (realized (grey)), planned (orange), and not planned (blue)) (REI: Reduction of Environmental Impact).

The most common realized action involves the reduction of environmental impacts in terms of efficiency in the management of waste and its recycling, followed by protection of the natural environment (such as reducing the use of fertilizers and pesticides), and pollution prevention (such as reduction of polluting emissions and wastewater treatment). This confirms the tendency to consider CSR mainly as an environmental issue (3.1). It is important to underline that the investigated actions and aspects are overall realized or planned: development of the local economy through local purchasing; thermal insulation of buildings and/or production of energy from renewable sources; financial contribution to the activities and projects of the local community (e.g., donations, sponsorships, promotion, and enhancement of the territory and development of networks between companies); and reduction of environmental impact in terms of energy saving.

The highest rate of not planned actions regard: the use of codes of conduct, or ethical certifications (such as code of ethics, SA 8000, OHSAS 18001, ISO 14000, EMAS, Eco-Label, and EPD), which are definitely considered less urgent, and intervention to reduce the environmental impact of transportation, which is considered relevant in order to guarantee a company's economic sustainability and, therefore, unavoidable.

With the aim of specifically assessing the importance of environmental aspects of CSR implemented by the respondents (Q 3.1, Figure 5), all of the wine companies confirm they take care of grapes safety, which implies the adequate management strategy of phytosanitary treatments and the absence of residues at harvesting time, confirming the increased risk perception with respect to agrochemicals exposure, and what is reported in Figure 4 about the protection of the natural environment. Less importance is given to the selection of sustainable packaging; this could be due to a lack of information and innovative technology offers. 


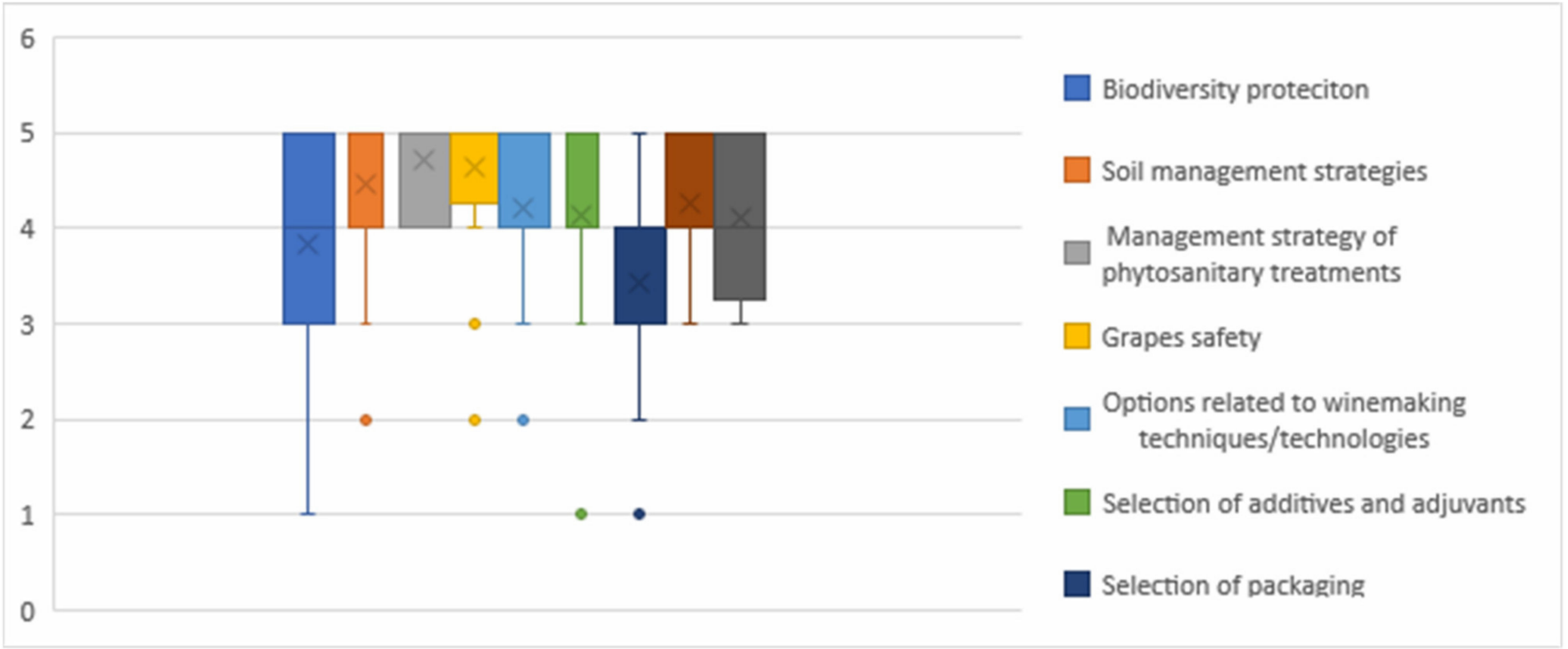

Figure 5. Importance of different environmental aspects of CSR (1 low importance; 5 high importance).

\subsection{Business Performance Implications}

By considering the contribution of sustainability to wine companies' economic improvement, the majority of the respondents reported that it increases the efficiency in resource use, while less relevance is attributed to its ability to lower costs and taxes and reduce financial and operational risk (Figure 6). Sustainability, in terms of product/brand differentiation, is recognized as a factor which highly increases brand strength and moderately increases consumer loyalty, justifies a premium price for the product, and provides chances to enter new markets (Figure 7).

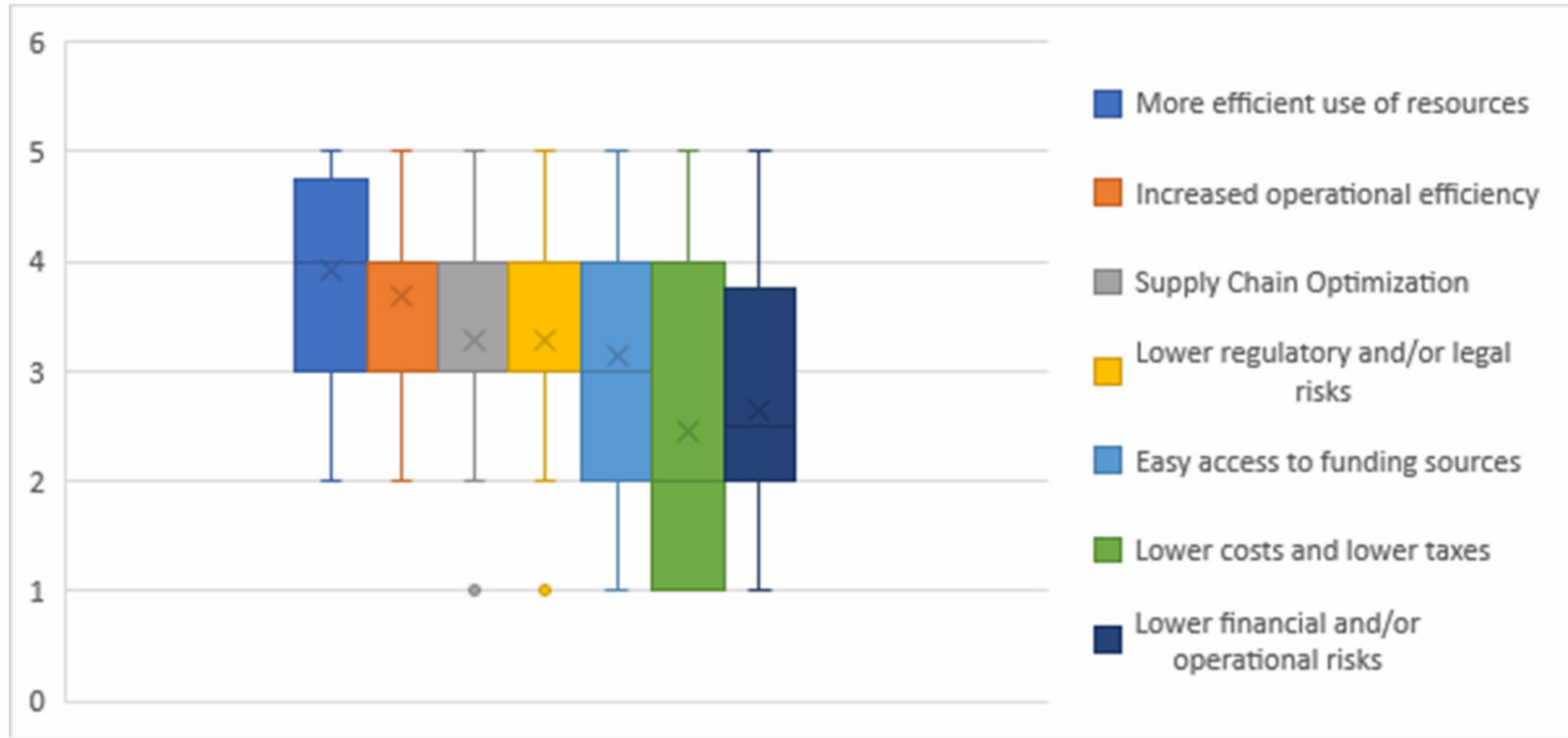

Figure 6. Sustainability impact on economic aspects of wine businesses (1 low impact; 5 high impact). 


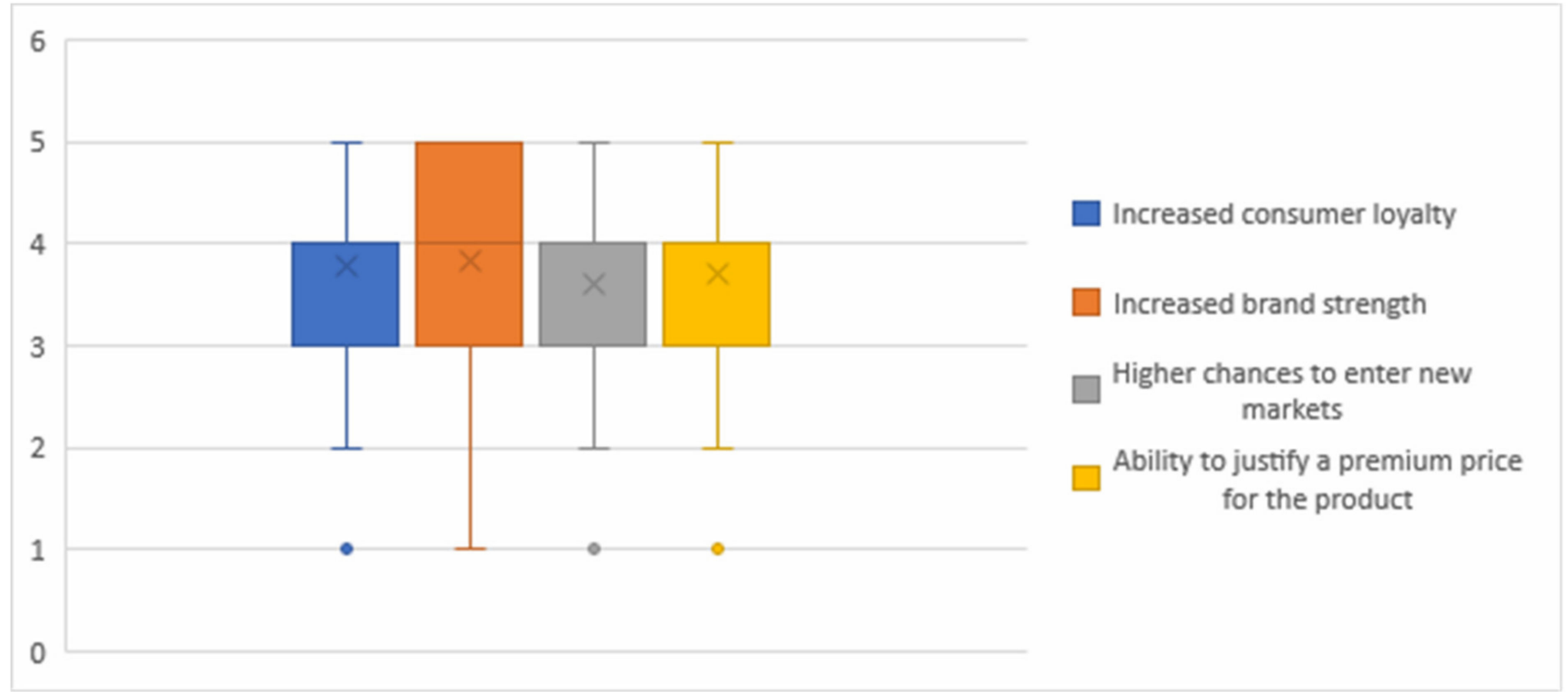

Figure 7. Impact of sustainability in terms of product/brand differentiation (1 low impact; 5 high impact).

None of the respondents reported negative unexpected changes after implementing CSR practices. A respondent stated that he has "greater awareness of what is being done and the impact of each of his company actions" and that "customers are starting to demonstrate interest in CSR activities of his company", another one reported an "increased awareness and interest shown by employees and consumers".

\subsection{CSR Communication}

According to the answers to Q 4.1, the most common strategies to communicate commitment and actions in terms of CSR include social media, company websites, brochures, and other information materials. Two respondents also added that by "making direct selling, I have the opportunity to communicate without means about my commitment to CSR, while showing what I really do day by day" and that "I communicate my CSR commitment directly speaking with clients". A quarter of respondents declared not to communicate their CSR commitment at all.

All respondents agree that coherence between commitments made and what is actually done in terms of CSR is an important communication aspect which brings real strategic benefits, such as a better reputation and better relationships with employees.

\subsection{Typology Matrix of Companies Engaging in Sustainability}

The typology matrix (Figure 8) proposed by Gabzdylova et al. (2009) was applied to the studied wine companies in order to investigate the relation between the extent of CSR practices implemented (Figure 4) and the sustainability drivers (mandatory or voluntary) they need to face.

The matrix distinguishes wine companies among: minimalist (lower left quadrant) with limited extent of CSR practices to comply to external needs/requests; value driven (lower right quadrant) with limited, but voluntary CSR practices; reputation seeking (upper left quadrant) with enhanced CSR practices in order to meet compliance to external requests; excellence seeking (upper right quadrant) with enhanced and voluntary CSR practices. 


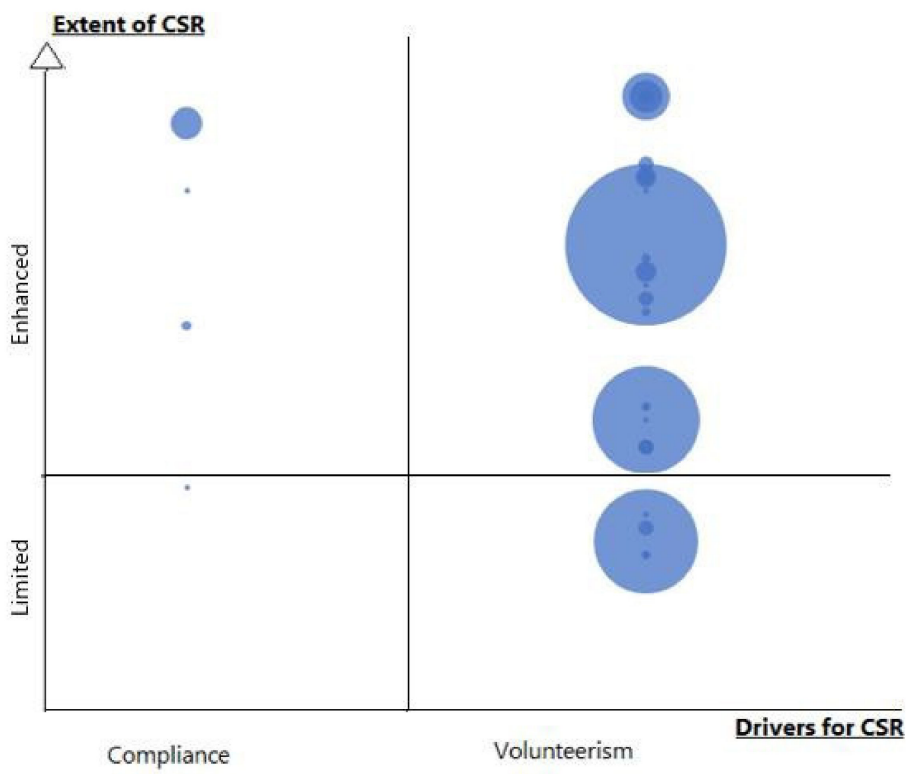

Figure 8. Typology matrix. Extent of CSR (from limited to enhanced) and its relation to the type of CSR drivers (compliance or volunteerism). The vertical axis reports to what extent the researched wine companies have realized or are planning to realize CSR actions previously reported in Figure 4 (Score of Realized actions: 2; Planned action: 1; Not planned actions: 2), while the horizontal axis shows if actions are voluntary $(+1)$, or undertaken in order to comply to external needs $(-1)$. The bubbles represent the interviewed wine companies, and the bubble dimension is directly related to their annual revenue (that was previously reported in Table 2).

\section{Discussion of Results}

The reduction of environmental impact by decreasing the use of fertilizers, pesticides, and emissions in the environmental media, better management of waste, reducing energy and resource use, as well as development of the local economy through local purchasing, and promotion of the territory in order to maintain functioning societies, are key challenges for many wine companies and they will influence todays and future business strategies.

This is clearly perceived by the participants of this study that, even if they don't consider themselves sufficiently informed about CSR, they reported many initiatives related to CSR that are already in place in their company or are planned. Even if the participants in this study don't consider Italian consumers to be particularly interested in the sustainability of wine production, market trends are going towards this direction $[44,45]$ and many consumers are willing to pay a premium price for sustainable wine and products $[46,47]$. Indeed, to compete on the market, mere economic sustainability is no longer sufficient, but companies are required to engage in a special commitment to their environmental and social responsibilities. This reflects, somehow, on the intended or implied business strategies of the cases studied in the present paper: actions in place or planned with respect to CSR are numerous, but generally related to environmental issues with scarce development or social and cultural pillars. The commitment to CSR reported by interviewees is mainly voluntary (as shown by the typology matrix), in coherence with what was reported by De Steur [31] for the Tuscany and Emilia Romagna Italian regions. It has been shown that companies are pushed to implement sustainable practices and are asked to revise their internal processes, and to succeed they need new knowledge and leading actors [48].

The declared low level of theoretical information about CSR by respondents is strongly compensated by their concrete awareness about CSR aspects and the related actions that have been implemented by the wine companies. This detected dichotomy between theoretical knowledge of CSR and real commitment by wine companies should be further assessed in future studies in order to identify possible causes and impacts on the sector. Indeed, even if CSR is considered by larger companies a necessary condition for a better brand 
reputation [49], our research shows that smaller companies are more aware of the role it plays if they are to thrive in the market and respond to increasingly demanding and selective consumers. Moreover, the recognition and commitment to CSR strategies are strictly related to the personal commitment and ethic of the entrepreneur himself, especially for individual enterprises [50]. Furthermore, corporate owners are more prone to undertaking sustainability initiatives with capabilities for building orientations [51], and more inclined to innovate for material and energy efficiency, delivering socio-environmental metrics in their value proposition and accounting for sustainability, compared to small companies [52]. This could relevantly influence ownership and employee awareness and knowledge about CSR, as well as the results and the communication to consumers of the undertaken actions.

Entrepreneurial commitment to sustainability does not always imply sustainability certifications or standard compliances: the perception of being a responsible entrepreneur may differ among company owners and is related to personal values and ethics. This is confirmed in the results shown by Gabzdylova et al. [42].

\section{Conclusions and Discussion}

This study aimed to investigate the level of awareness and implementation of Corporate Social Responsibility actions in wine companies located in Veneto and Friuli Venezia Giulia (Italy). The methodology applied in this study included the development of a questionnaire based on the conceptual model of the study (Figure 1), which identifies six main areas of assessment for CSR: awareness, market drivers, obstacles, practices, business performances implications, and communication.

One of the limitations of this study is represented by the quite low questionnaire response rate, which could be due to the data collection period, since it coincides with holiday leaves, and it is very close to the harvesting time. Furthermore, the sample could be self-selected, since the more responsible entrepreneurs and managers could be more prone to participate in this kind of research. Those variables could have affected the results, which should be interpreted with caution and validated with further quantitative research that includes a wider sample of wine companies. Considering that sustainability is a growing and expanding topic of research, the applied methodology and the developed questionnaire can be used, with appropriate adjustments, in order to collect the awareness about CSR and related actions implemented by companies in other contexts and sectors in the world. The results presented in this study give a general picture on how sustainability is influencing the production and marketing strategies of wine companies. Nevertheless, the discussions presented for the specific questions cannot be extended to the entire Italian and European context, which are characterized by relevant regional differences in vineyard practices as consequences of different regional climates, industrial developments, population density, and culture, etc. Additional research in this field is, thus, required.

Supplementary Materials: Supplementary Materials are available at https://www.mdpi.com/ article/10.3390/su132313230/s1.

Author Contributions: Conceptualization, G.L. and L.P.; methodology, G.L. and L.P; proof reading and validation, E.C. and C.B.; investigation, L.B. and P.C.; writing—original draft preparation, G.L. and L.P.; review and editing, G.L., L.P. All authors have read and agreed to the published version of the manuscript.

Funding: PROINOS—Coltivare la sostenibilità, Programma di Sviluppo Rurale 2014-2020: ID Domanda 4113850.

Institutional Review Board Statement: Not applicable.

Informed Consent Statement: Not applicable.

Data Availability Statement: Data can be required to the corresponding author at gloria.luzzani@ccrs.uzh.ch.

Conflicts of Interest: The authors declare no conflict of interest. 


\section{References}

1. Caracciolo, F.; Cicia, G.; Del Giudice, T.; Cembalo, L.; Krystallis, A.; Grunert, K.G.; Lombardi, P. Human values and preferences for cleaner livestock production. J. Clean. Prod. 2016, 112, 121-130. [CrossRef]

2. Campbell, L.J. Why Should Corporations Behave in Socially Responsible Ways? An Institutional Theory of Corporate Social Responsibility. Acad. Manag. Rev. 2007, 32, 946-967. [CrossRef]

3. Russo, A.; Perrini, F. Investigating Stakeholder Theory and Social Capital: CSR in Large Firms and SMEs. J. Bus. Ethics 2010, 91, 207-221. [CrossRef]

4. UN General Assembly. Transforming our world: The 2030 Agenda for Sustainable Development, 21 October 2015, A/RES/70/1. Available online: https:/ / www.refworld.org/docid/57b6e3e44.html (accessed on 23 November 2021).

5. Mozell, M.R.; Thach, L. The impact of climate change on the global wine industry: Challenges \& solutions. Wine Econ. Policy 2014, 3, 81-89. [CrossRef]

6. Costa, J.M.; Vazc MEscalona, J.; Egipto, R.; Lopes, C.; Medrano, H.; Chaves, M.M. Modern viticulture in southern Europe: Vulnerabilities and strategies for adaptation to water scarcity. Agric. Water Manag. 2016, 164, 5-18. [CrossRef]

7. Paiola, A.; Assandri, G.; Brambilla, M.; Zottini, M.; Pedrini, P.; Nascimbene, J. Exploring the potential of vineyards for biodiversity conservation and delivery of biodiversity-mediated ecosystem services: A global-scale systematic review. Sci. Total Environ. 2019, 706, 135839. [CrossRef]

8. Millennium Ecosystem Assessment. In Ecosystems and Human Well-being: Synthesis; Island Press: Washington, DC, USA, 2005.

9. Mitchell, R.; Charters, S.; Albrecht, J.N. Cultural systems and the wine tourism product. Ann. Tour. Res. 2012, 39, 311-335. [CrossRef]

10. Moscovici, D.; Reed, A. Comparing wine sustainability certifications around the world: History, status and opportunity. J. Wine Res. 2018, 29, 1-25. [CrossRef]

11. European Commission. Organic Farming. 2020. Available online: https://ec.europa.eu/info/food-farming-fisheries/farming/ organic-farming_it (accessed on 4 April 2020).

12. Rete Rurale. Produzione Integrata. 2020. Available online: https://www.reterurale.it/produzioneintegrata (accessed on 4 April 2020).

13. VIVA Sustainability and Culture. 2020. Available online: http:/ /www.viticolturasostenibile.org/ (accessed on 26 March 2020).

14. California Sustainable Winegrowing Alliance. Sustainable Wine Growing. 2020. Available online: https://www. sustainablewinegrowing.org/certified-sustainable-winegrowing.php (accessed on 4 April 2020).

15. Oesterreich Wein. 2020. Available online: https://www.oesterreichwein.at/unser-wein/nachhaltigkeit-in-oesterreichsweingaerten/ zertifiziert-nachhaltig (accessed on 4 April 2020).

16. Lamastra, L.; Balderacchi, M.; Di Guardo, A.; Monchiero, M.; Trevisan, M. A novel fuzzy expert system to assess the sustainability of the viticulture at the wine-estate scale. Sci. Total Environ. 2016, 572, 724-733. [CrossRef]

17. Lamastra, L.; Suciu, N.; Novelli, E.; Trevisan, M. A new approach to assessing the water footprint of wine: An Italian case study. Sci. Total Environ. 2014, 490, 748-756. [CrossRef] [PubMed]

18. D'Ammaro, D.; Capri, E.; Valentino, F.; Grillo, S.; Fiorini, E.; Lamastra, L. Benchmarking of carbon footprint data from the Italian wine sector: A comprehensive and extended analysis. Sci. Total Environ. 2021, 779, 146416. [CrossRef]

19. Luzzani, G.; Lamastra, L.; Valentino, F.; Capri, E. Development and implementation of a qualitative framework for the sustainable management of wine companies. Sci. Total Environ. 2020, 759, 143462. [CrossRef]

20. Bonamente, E.; Scrucca, F.; Asdrubali, F.; Cotana, F.; Presciutti, A. The water footprint of the wine industry: Implementation of an assessment methodology and application to a case study. Sustainability 2015, 7, 12190-12208. [CrossRef]

21. Borsato, E.; Giubilato, E.; Zabeo, A.; Lamastra, L.; Criscione, P.; Tarolli, P.; Marinello, F.; Pizzol, L. Comparison of Water-focused Life Cycle Assessment and Water Footprint Assessment: The case of an Italian wine. Sci. Total Environ. 2019, 666, 1220-1231. [CrossRef]

22. Pattara, C.; Raggi, A.; Cichelli, A. Life Cycle Assessment and Carbon Footprint in the Wine Supply-Chain. Environ. Manag. 2012, 49, 1247-1258. [CrossRef]

23. Rugani, B.; Vázquez-Rowe, I.; Benedetto, G.; Benetto, E. A comprehensive review of carbon footprint analysis as an extended environmental indicator in the wine sector. J. Clean. Prod. 2013, 54, 61-77. [CrossRef]

24. Sun, Y.-Y.; Drakeman, D. Measuring the carbon footprint of wine tourism and cellar door sales. J. Clean. Prod. 2020, 266, 121937. [CrossRef]

25. Rinaldi, S.; Bonamente, E.; Scrucca, F.; Merico, M.C.; Asdrubali, F.; Cotana, F. Water and Carbon Footprint of Wine: Methodology Review and Application to a Case Study. Sustainability 2016, 8, 621. [CrossRef]

26. Borsato, E.; Zucchinelli, M.; D’Ammaro, D.; Giubilato, E.; Zabeo, A.; Criscione, P.; Pizzol, L.; Cohen, Y.; Tarolli, P.; Lamastra, L.; et al. Use of multiple indicators to compare sustainability performance of organic vs conventional vineyard management. Sci. Total Environ. 2020, 711, 135081. [CrossRef] [PubMed]

27. Broccardo, L.; Zicari, A. Sustainability as a driver for value creation: A business model analysis of small and medium entreprises in the Italian wine sector. J. Clean. Prod. 2020, 259, 120852. [CrossRef]

28. Bentivogli, C.; Quintiliani, F.; Sabbatini, D. “Le reti di imprese”, Questioni di Economia e Finanza, No. 152 (Febbraio). 2013 , pp. 5-33. Available online: https:/ / www.bancaditalia.it/pubblicazioni/qef/2013-0152/QEF_152.pdf (accessed on 29 November 2021).

29. Santini, C.; Cavicchi, A.; Casini, L. Sustainability in the Wine Industry: Key Questions and Research Trends. Agric. Food Econ. 2013, 1, 1-14. [CrossRef] 
30. Grimstad, S. Developing a framework for examining business-driven sustainability initiatives with relevance to wine tourism clusters. Int. J. Wine Bus. Res. 2011, 23, 62-82. [CrossRef]

31. De Steur, H.; Temmerman, H.; Gellynck, X.; Canavari, M. Drivers, adoption, and evaluation of sustainability prac-tices in Italian wine SMEs. Bus. Strategy Environ. 2020, 29, 744-762. [CrossRef]

32. Gilinsky, A., Jr.; Newton, S.K.; Atkin, T.S.; Santini, C.; Cavicchi, A.; Casas, A.R.; Huertas, R. Perceived efficacy of sustainability strategies in the US, Italian, and Spanish wine industries: A comparative study. Int. J. Wine Bus. Res. 2015, 27, 164-181. [CrossRef]

33. Mariani, A.; Vastola, A. Sustainable winegrowing: Current perspectives. Int. J. Wine Res. 2015, 7, 37-48. [CrossRef]

34. Dodds, R.; Graci, S.; Ko, S.; Walker, L. What drives environmental sustainability in the New Zealand wine industry? Int. J. Wine Bus. Res. 2013, 25, 164-184. [CrossRef]

35. Trevisotoday. Referendum Sui Pesticidi a Conegliano: «Sbagliato Impedire il Voto Dei Cittadini». 2019. Available online: https:/ / www.trevisotoday.it/ politica/conegliano-referendum-pesticidi-25-settembre-2019.html (accessed on 15 August 2020).

36. Ponte, S. Bursting the bubble? The hidden costs and visible conflicts behind the Prosecco wine 'miracle'. J. Rural. Stud. 2021, 86, 542-553. [CrossRef]

37. Basso, M. Land-use changes triggered by the expansion of wine-growing areas: A study on the Municipalities in the Prosecco's production zone (Italy). Land Use Policy 2019, 83, 390-402. [CrossRef]

38. Visentin, F.; Vallerani, F. A Countryside to Sip: Venice Inland and the Prosecco's Uneasy Relationship with Wine Tourism and Rural Exploitation. Sustainability 2018, 10, 2195. [CrossRef]

39. Pappalardo, S.E.; Gislimberti, L.; Ferrarese, F.; De Marchi, M.; Mozzi, P. Estimation of potential soil erosion in the Prosecco DOCG area (NE Italy), toward a soil footprint of bottled sparkling wine production in different land-management scenarios. PLoS ONE 2019, 14, e0210922. [CrossRef] [PubMed]

40. Basso, M.; Vettoretto, L. Reversal sprawl. Land-use regulation, society and institutions in Proseccotown. Land Use Policy 2020, 99, 105016. [CrossRef]

41. Basso, M.; Fregolent, L. Fighting Against Monocultures: Wine-Growing and Tourism in the Veneto Region. In Social Movements and Public Policies in Southern European Cities. Urban and Landscape Perspectives; Fregolent, L., Nello, O., Eds.; Springer: Cham, Switzerland, 2021; Volume 21. [CrossRef]

42. Gabzdylova, B.; Raffensperger, J.F.; Castka, P. Sustainability in the New Zealand wine industry: Drivers, stakeholders and practices. J. Clean. Prod. 2009, 17, 992-998. [CrossRef]

43. ISTAT-Istituto Nazionale di Statistica. Available online: http:/ / dati.istat.it/ (accessed on 15 August 2020).

44. Pomarici, E.; Vecchio, R. Millennial generation attitudes to sustainable wine: An exploratory study on Italian con-sumers. J. Clean. Prod. 2014, 66, 537-545. [CrossRef]

45. OPERA Research Center. Sustainability, the New Frontier for the Wine Sector. 2019. Available online: https://issuu.com/ operaresearchcenter/docs/10_eng_web_alta_sost_conv_roma (accessed on 3 September 2020).

46. Berghoef, N.; Dodds, R. Potential for sustainability eco-labeling in Ontario's wine industry. Int. J. Wine Bus. Res. 2011, 23, $298-317$. [CrossRef]

47. Soregaroli, C.; Ricci, E.C.; Stranieri, S.; Nayga, R.M., Jr.; Capri, E.; Castellari, E. Carbon footprint information, prices, and restaurant wine choices by customers: A natural field experiment. Ecol. Econ. 2021, 186, 107061. [CrossRef]

48. Siebenhüner, B.; Arnold, M. Organizational learning to manage sustainable development. Bus. Strat. Environ. 2007, 16, 339-353. [CrossRef]

49. Alon, A.; Vidovic, M. Sustainability Performance and Assurance: Influence on Reputation. Corp. Reput. Rev. 2015, 18, 337-352. [CrossRef]

50. Fuller, T.; Tian, Y. Social and Symbolic Capital and Responsible Entrepreneurship: An Empirical Investigation of SME Narratives. J. Bus. Ethics 2006, 67, 287-304. [CrossRef]

51. Sirsly, C.-A.T.; Sur, S. Strategies for sustainability initiatives: Why ownership matters. Int. J. Bus. Soc. 2013, 13, 541-550. [CrossRef]

52. Aguilar-Fernández, M.E.; Otegi-Olaso, J.R. Firm size and the business model for sustainable innovation. Sustainability 2018, 10, 4785. [CrossRef] 